\title{
Improved Cycling Performance of Si Thin Film Anode for Lithium Rechargeable Batteries
}

\author{
Hong-Sik Kim, Myoung-Gi So, and Sung-Man Lee* \\ Department of Advanced Materials Science and Engineering, Kangwon National University, Chuncheon, \\ Kangwon 200-701, Korea. "E-mail: smlee(akangwon.ackr \\ Received September 10, 2008
}

\begin{abstract}
We investigated efficient ways to improve the cycling performance of Si film electrode as an anode of Li-ion batteries. The Si films were deposited on a $\mathrm{Cu}$ or $\mathrm{Ni}$ foil by a magnetron sputtering method. In view of the fact that the improvement of the cycling performance can be achieved by preventing the electrical contact loss of active material, $\mathrm{Si}$ with the current collecting substrate, we proposed the approaches, the surface morphology obtained by preferential deep etching at grain boundary regions of the substrate, and the introduction of the gluing layer into the $\mathrm{Si}$ film/substrate interface. These trials impressively improve the cycling performance of Si film electrodes. It also appears that the current density used during cycling tests may play a crucial role in the cracking behavior of $\mathrm{Si}$ films. The superior cyclability is obtained by forming small and uniform microislands in Si film electrodes.
\end{abstract}

Key Words : Si fillm anode, Li-ion secondary batteries, Magnetron sputtering, Surface morphology, Adhesion

\section{Introduction}

There is growing demand for lithium ion batteries with high energy density. The Li-Si system as anodes has attracted great attention because of its highest theoretical capacity. The theoretical specific capacity of pure silicon is 4200 $\mathrm{mAh} / \mathrm{g}$, much larger than that of $372 \mathrm{mAl} / \mathrm{g}$ for graphitic carbons. However, it is well known that poor cyclability is observed due to a large volume change during cycling resulting in mechanical and electrical degradation. ${ }^{1-5}$ Efforts to solve the cyclability problem have so far been made. ${ }^{\text {r-11 }}$ It has been reported that the amorphous $\mathrm{Si}$ thin film electrodes fabricated by various deposition techniques showed promising results related to specific capacity and cyclability. ${ }^{12-20}$ It also appeared that the cyclability is dependent on the surface roughness of the current collector. ${ }^{17-22}$ In general, it is believed that the capacity fade on cycling arises from the loss of electrical contact between active Si film and current collector. Therefore, in the present work, we tried to provide a method to attain good cycle performance of Si thin-film anodes in view of enhancing the electrical contact between Si film and substrate.

\section{Experimental}

Si thin films were prepared by r.f. magnetron sputtering from a $5.08 \mathrm{~cm}$ diameter $\$$ i target $(99.99 \%)$ on to the current collector of copper foil with/without surface modification. The surface modification of the substrate was performed by etching with two kinds of aqueous solution of $\mathrm{FeCl}_{3}$ and $\mathrm{HNO}_{3}$, in which the concentration and etching time were varied in the range of 0.4 to $3.5 \mathrm{M}$ and $1-3 \mathrm{~min}$, respectively. The thickness of the films was $5000 \AA$. The deposition chamber was pumped down to a base pressure of $2 \times 10^{-6}$ Torr prior to the introduction of the argon gas. The working pressure was kept at $5 \mathrm{mTont}$.

The surface morphology of the films was examined using field emission scanning electron microscopy (FESEM). The electrochemical measurements of the Si film electrodes were performed in two electrode-system using 2016 coin cells where pure $\mathrm{Li}$ foils were used as counter electrode. The electrolyte used was $1 \mathrm{M} \mathrm{LiPF}_{6}$ solution in a ethylene carbonate (EC)/diethyl carbonate (DEC) (1:1 by volume, provided by Techno Semichem Co., Ltd, South Korea). All cells were assembled in an argon-filled glove box and cycled at $100 \mu \mathrm{A} / \mathrm{cm}^{2}$ at $30^{\circ} \mathrm{C}$ unless otherwise stated.

\section{Results and Discussion}

Since it has been reported that Si films deposited on a roughened surface of copper foil shows a good electrochemical behavior compared to $\mathrm{Si}$ film formed on a flat substrate, ${ }^{17-20}$ we investigated the effect of surface morphologies of Cu current collector, induced by different etching conditions of etching solution, time, and concentration, on the electrochemical performance of Si film electrodes formed on Cu current collector.

Figure 1 shows FE-SEM images of differently roughened surfaces of $\mathrm{Cu}$ foil. The details of the etching for those samples are given in Table 1. In particular, it is worthwhile to note the surface morphology of the sample shown in Figure 1(d), in which rather wide and deep valleys are developed at the grain boundary regions.

Figure 2 shows the cycle performance of the Si films deposited on the Cu substrates corresponding to those shown in Figure 1. It appears that the cyclability depends on the surface morphology of $\mathrm{Cu}$ substrate.

The effect of the surface roughness of the substrate on improving cyclability results from the formation of micro columnar structure during charge and discharge. A mode- 

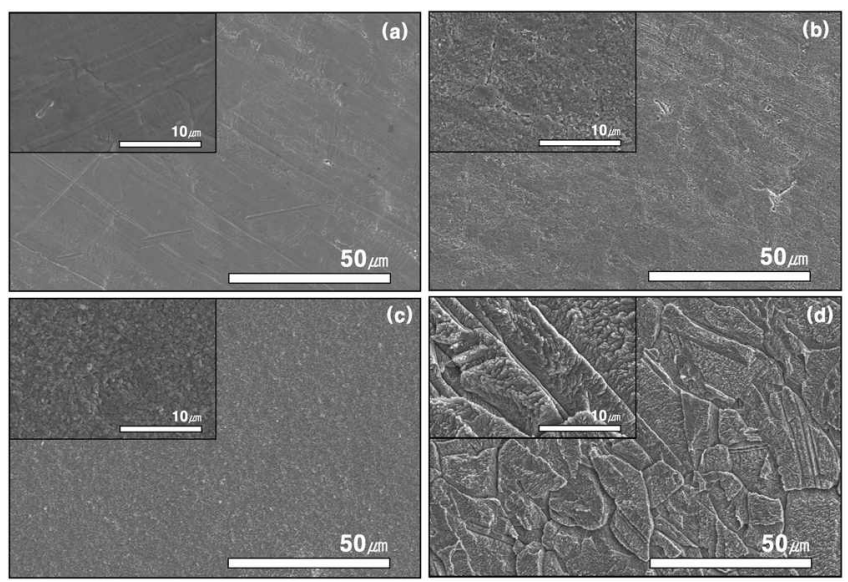

Figure 1. FE-SEM images of differently roughened surfaces of $\mathrm{Cu}$ foil. (a) Substrate A (not etched), (b) Substrate B (etched with $\mathrm{HNO}_{3} / \mathrm{H}_{2} \mathrm{O}$ ), (c) Substrate $\mathrm{C}$ (ctched with $\mathrm{FeCl}_{3} / \mathrm{H}_{2} \mathrm{O}$ ), (d) Substrate $\mathrm{D}$ (ctehed with $\mathrm{FeCl}_{3} / \mathrm{HCl} / \mathrm{H}_{2} \mathrm{O}$ ).

Table 1. The details of the etching condition for Cu substrate

\begin{tabular}{ccc}
\hline Substrate & Etchant & Etching time (min.) \\
\hline A & Not etched & 0 \\
B & $50 \mathrm{~mL} \mathrm{HNO}(65 \%)+50 \mathrm{~mL} \mathrm{H}_{2} \mathrm{O}$ & 3 \\
C & $2.5 \mathrm{~g} \mathrm{FeCl}_{3}+60 \mathrm{~mL} \mathrm{H} \mathrm{H}_{2} \mathrm{O}$ & 5 \\
D & $5 \mathrm{~g} \mathrm{FeCl}_{3}+15 \mathrm{~mL} \mathrm{HCl}+60 \mathrm{~mL} \mathrm{H} \mathrm{H}_{2} \mathrm{O}$ & 1 \\
\hline
\end{tabular}

rately roughened surface of $\mathrm{Cu}$ foil provide a well selforganized micro columnar structure of $\mathrm{Si}$ film, thereby reducing the stress and strain caused by its volume change during cycling. ${ }^{20}$ From this point of view, it is meaningful to note that the electrode D (formed on the substrate D, as in Figure 1(d)) reveals better capacity retention than the others as shown in Figure 2.

Nevertheless, since the capacity fade on cycling is basically caused by the loss of electrical contact between active material and current collector, it is important to find a method to enhance the adhesion between active material ( $\mathrm{Si}$ )

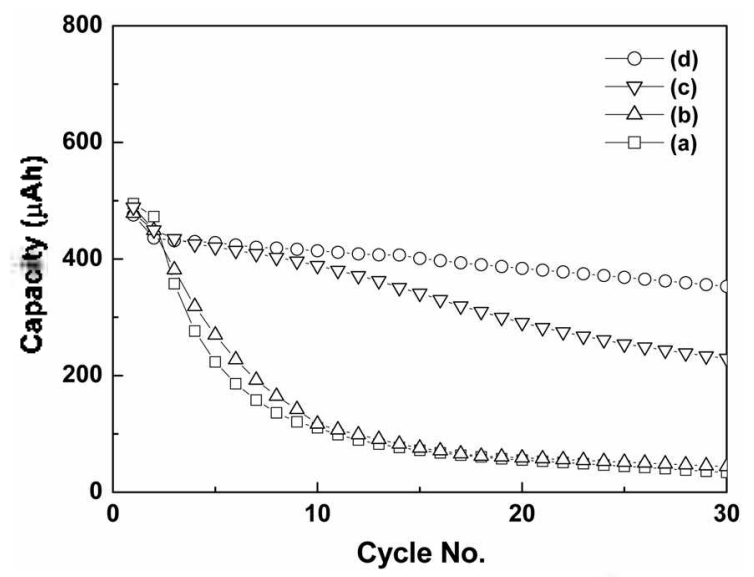

Figure 2. The capacity vs. cycle number of $5000 \mathrm{~A}$ thick Si film clectrodes. (a) Substrate $\Lambda$ (not etched), (b) Substrate B (ctched with $\mathrm{HNO}_{3} / \mathrm{H}_{2} \mathrm{O}$ ), (c) Substrate $\mathrm{C}$ (etched with $\mathrm{FeCl}_{3} / \mathrm{H}_{2} \mathrm{O}$ ), (d) Substrate D (etched with $\mathrm{FeCl}_{3} / \mathrm{HCl}_{2} / \mathrm{H}_{2} \mathrm{O}$ ).

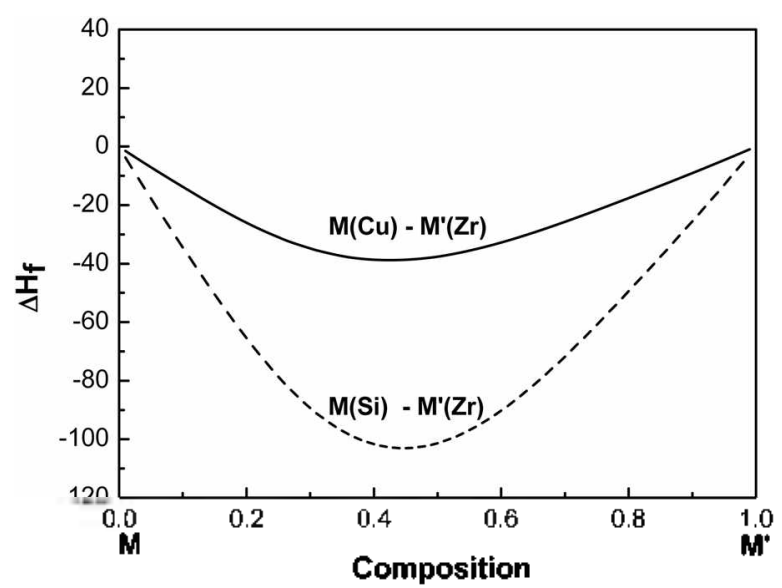

Figure 3. Heat of formation calculated by Miedema model.

and current collector $(\mathrm{Cu})$. At this background, the insertion of a gluing layer between a $\mathrm{Cu}$ current collecting substrate and a Si film electrode would be a promising approach to improve the stability of electrode/substrate interface. ${ }^{23}$ In the present work, Zirconium $(\mathrm{Zr})$ is chosen as the gluing layer because $\mathrm{Zr}$ has a strong chemical affinity with $\mathrm{Si}$ as well as $\mathrm{Cu}$, as deduced from their large negative heat of mixing of the constituent elements. ${ }^{24}$ The heat of mixing can be calculated according to Midema's semi-expirical model (Fig. $3)^{2426}$ Figure 4 shows the effect of the $\mathrm{Zr}$ gluing layer on the cycle perfonmance of $\mathrm{Si}$ films deposited on a moderately roughened surface of $\mathrm{Cu}$ foil as shown in Figure 1(d). In the case of sample with the gluing layer, a $100 \AA$ thick $\mathrm{Zr}$ film was deposited on the Cu substrate prior to a Si film deposition. The cyclability of Si film electrode is significantly improved by applying the $\mathrm{Zr}$ gluing layer between $\mathrm{Si}$ film and $\mathrm{Cu}$ substrate. The SEM images of the Si film electrodes with/without $\mathrm{Zr}$ gluing layer after the first and 18 th cycles are illustrated in Figure 5. It is observed that they have so different electrode structures although cracks are formed in both samples after cycling. This characteristic difference becomes quite definite in the SEM images observed after the 18 th cycle, as shown in Figure 5(c) and (d). For the electrode

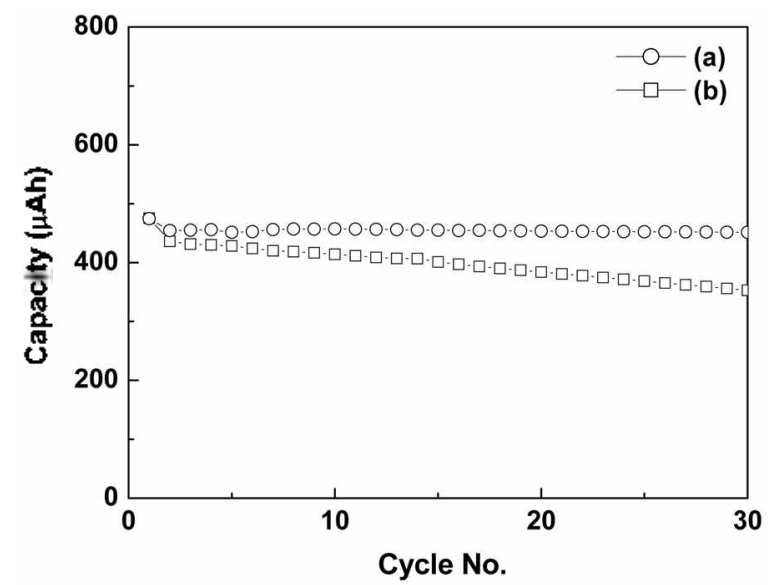

Figure 4. The capacity retention vs. cycle number of Si films (a) with or (b) without gluing layer. 

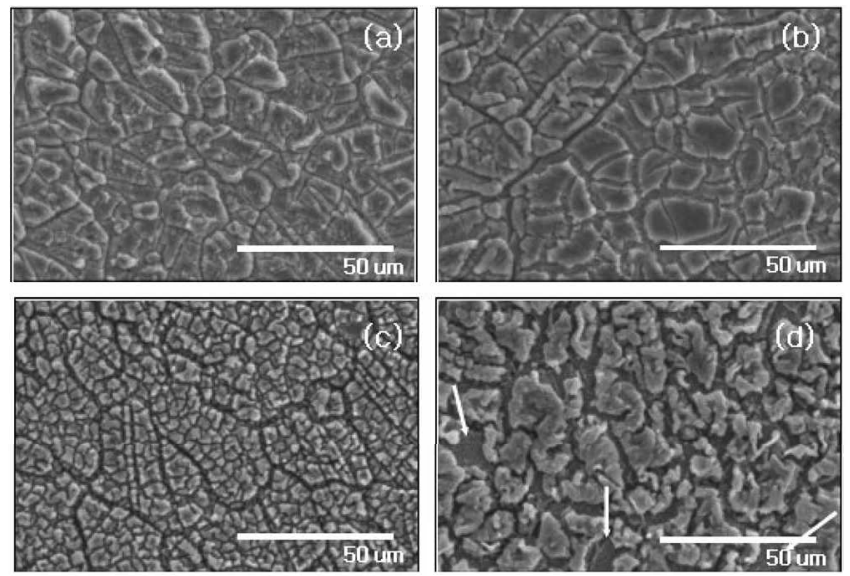

Figure 5. FE-SEM inages of Si film elcetrodes after the first cycle (a), (b) and 18 th cycles (c), (d) with or without $\mathrm{Zr}$ gluing layer: (a) and (c), with $\mathrm{Zr}$ gluing layer, (b) and (d) without $\mathrm{Zr}$ gluing layer.

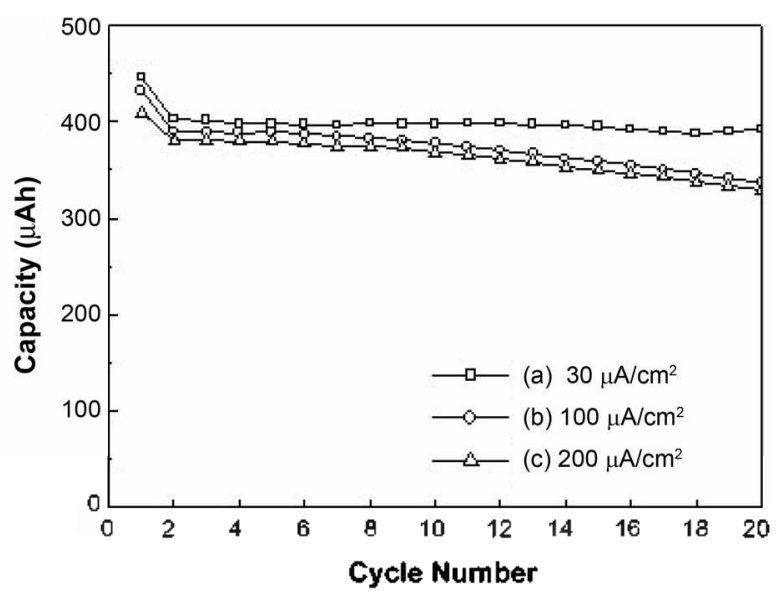

Figure 6. The capacity vs. cycle number of Si films without the $\mathrm{Zr}$ gluing layer on the substrate D at different current densities: (a) 30 $\mu \Lambda$, (b) $100 \mu \Lambda$, (c) $200 \mu \Lambda$.
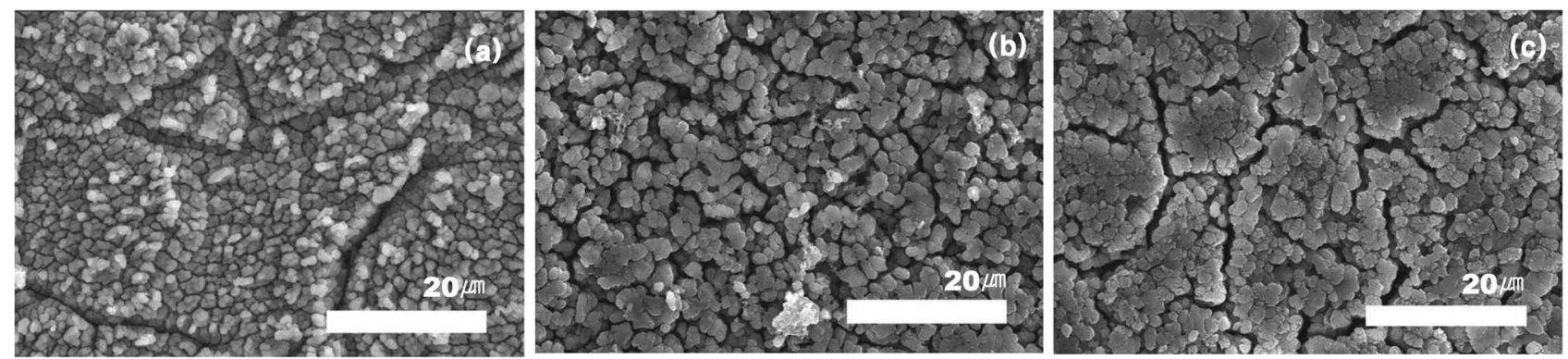

Figure 7. FE-SEM inages of $5000 \lambda$ thick Si film deposited on substrate (d) after 20 cycles.

with the $\mathrm{Zr}$ gluing layer, there are wide gaps in accordance with the grain boundary profile of the $\mathrm{Cu}$ substrate as shown in Figure I(d) and the narrow gaps are formed within the islands surrounded by the wide gaps (i.e., within the grain of $\mathrm{Cu}$ substrate), leading to the small and uniform dimension of the micro-islands divided by the narrow gaps. The formed micro columnar structure appears to be stable during cycling. On the other hand, for the electrode without the $\mathrm{Zr}$ layer, the islands and cracks are random and the dimensions of the island are large compared with those of the electrode with the $\mathrm{Zr}$ gluing layer. It can be also observed that some islands were detached from the substrate (marked as arrows in Figure 5(d)). It is also found that the formation of micro columnar structure in Si film electrodes is controlled by the current density during charge/discharge cycling, thereby affecting their cycling stability. Figure 6 shows the cycle perfornance of Si films deposited without the $\mathrm{Zr}$ gluing layer on the substrate D in Figure I(d), in which the electrodes were galvanostatically cycled at different current densities of 30,100 and $200 \mu \mathrm{A} / \mathrm{cm}^{2}$. The capacity retention was much better at a low current density of $30 \mu \mathrm{A} / \mathrm{cm}^{2}$ than at higher current densities of 100 and $200 \mu \mathrm{A} / \mathrm{cm}^{2}$. This seems to be closely related to the mechanical cracking behavior of Si film electrodes in the early stage of cycling as illustrated in Figure 7. For the electrode cycled at $30 \mu \mathrm{A} /$ $\mathrm{cm}^{2}$, small and uniform micro-islands were formed within the islands surrounded by the wide gaps associated with the grain boundary profile as shown in Figure 7(a), which is similar to the feature of Figure 5(c), while when cells are cycled at higher current densities of 100 and $200 \mu \mathrm{A} / \mathrm{cm}^{2}$, larger islands formed and cracking was random. In the latter case, especially, it is noticeable that there is no wide gaps in accordance with the grain boundary profile of the $\mathrm{Cu}$ substrate (Fig. 7(b) and (c)). Therefore, these results indicate that the formation of small and uniform micro islands in $\mathrm{Si}$ films in the initial cycling stage would be a very promising solution to overcome the capacity fading problem during cycling when combined with the optimized surface-roughening of $\mathrm{Cu}$ substrate.

\section{Conclusion}

We tried to find some methods to improve the cycle performance of a Si film deposited on a current collecting substrate. The critical factor to realize improved performance in cyclability is to maintain a good contact between the deposited Si film and $\mathrm{Cu}$ substrate during cycling. The surface roughness of substrate plays an important role for the adhesion improvement, especially the surface morphology obtained by preferential deep etching at grain boundary regions is suggested to be effective. The introduction of the $\mathrm{Zr}$ gluing layer into the $\mathrm{Si}$ film/Cu substrate interface improves significantly the performance. The cracking behavior of Si film is also dependent on the current density used 
in the cycle test. The superior cyclability is obtained by forming small and uniform micro-islands in Si film electrodes.

\section{References}

1. Huggins, R. A. Solid State Lonics 1998, /13-/15, 57.

2. Li, H.; Huang, X.; Chen, L.; Wu, Z.; Liang. Y. Electrochen. SolidState Lett, 1999, 2, 547.

3. Winter, M.; Besenhard, J. O. Electrochim. Acta 1999, 45, 31.

4. Doh, C. H.; Shin, H. M.; Kim, D. H.; Chung, Y. D.; Moon, S. I.; Jin, B. S.; Kim, H. S.; Kim, K. W.; Oh, D. H.; Veluchamy, A. Bull. Korean Chem. Soc. 2008, 29, 309-312.

5. Kim, H. S.; Chung, K. Y.; Cho, B. W. Bull. Korean Chem. Soc. 2008, 29, 1965-1968.

6. Hwang, S. M.; Lee, H. Y.; Jang, S. M.; Lee, S. M.; Lee, S. J.; Baik, H. K.; Lee, J. Y. Electrochem. Solid-State Lett, 2001, 4, 97.

7. Yoshio, M.; Wang, H.; Fukuda, K.; Umeno, T.; Dimov, N.; Ogumi, Z. J. Electrochem. Soc. 2002, 149, 1598.

8. Dimov, N.; Kugino, S.; Yoshio, M. Electrochim. Acta 2003, 48, 1579.

9. Yang, J.; Wang, B. F.; Wang, K.; Liu, Y.; Xie, J. Y.; Wen, Z. S. Electrochem. Solid-State Lett. 2003, 6, Al54.

10. Lee, H. Y.; Lee, S. M. J. Power Sources 2002, 112, 649.

II. Dong, H.; Ai, X. P.; Yang, H. X. Electrochem. Conmum. 2003, 5 , 952.

12. Jung, H.; Park, M.; Yoon, Y. G.; Kim, G. B.; Joo, S. K. J. Power
Sources 2003, 115, 346.

13. Ohara, S.; Suzuki, J.; Sekine, K.; Takamura, T. J. Power Sources 2004, $136,303$.

14. Maranchi, J. P.; Hepp, A. F.; Kumta, P. N. Electrochen. SolidState Lett. 2003, 6, Al98.

15. Graetz, J.; Ahn, C. C.; Yazami, R.; Fultz, B. J. Electrochem. Soc. 2004, 151, A698.

16. Baranchugov, V.; Markevich, E.; Pollak, E.; Salitra, G.; Aurbach, D. Electrochem. Commun. 2007, 9. 796.

17. Lee, K. L.; Jung, J. Y.; Lee, S. W; Moon, H. S.; Park, J. W. J. Power Sounces 2004, 129,270.

18. Takamura, T.; Ohara, S.; Uehara, M.; Suzuki, J.; Sekine, K. $J$. Power Sources 2004, 129, 96 .

19. Uehara, M.; Suzuki, J.; Tamura, K.; Sekine, K.; Takamura, T. $J$. Power Sources 2005, 146, 411

20. Yin, J.; Wada, M.; Yamamolo, K.; Kilano, Y.; Tanase, S.; Sakai, T. J. Electrochem. Soc. 2006, 153, A472.

21. Cho, G. B.; Cho, K. K.; Kim, K. W. Mater: Lett, 2006, 60, 90.

22. Zhang, T.; Zhang, H. P.; Yang, L. C.; Wang. B.; Wu, Y. P.; Takamura, T. Electrochim. Acta 2008, 53, 5660 .

23. Lee, S. J.; Lee, H. Y.; Park, Y. S.; Baik, H. K.; Lee, S. M. J. Power Sources 2003,119-121, 117.

24. Miedema, A. R. Philips Techol. Rev, 1976, 36, 217

25. Midema, A. R.; de Chatel, P. F.; de Boer, F. R. Plysica 1980, $J O O B, 1$.

26. Niessan, A. K.; de Boer, F. R.; Boom, R.; de Chatel, P. F.; Mattens, W. C. M.; Midema, A. R. CALPHAD 1983, 7,51. 